\title{
AS NICSPS E A CONTABILIDADE GOVERNAMENTAL DE PAÍSES EM DESENVOLVIMENTO
}

\section{IPSASS AND GOVERNMENTAL ACCOUNTING OF DEVELOPING COUNTRIES}

\section{LAS NICSPS Y LA CONTABILIDAD GUBERNAMENTAL DE PAÍSES EN VÍAS DE DESARROLLO}

\author{
JAMES L. CHAN \\ Professor Emérito de Contabilidade da Universidade de Illinois em Chicago, co-fundador do \\ CIGAR (Comparative International Government Accounting Research) \\ Professor por indicação especial do Instituto de Ciência Fiscal, China, desde 2004 \\ Professor consultor, Universidade de Economia e Finanças de Xangai, desde 1994 \\ jimchan@uic.edu
}

\section{RESUMO}

Com o objetivo de alcançarem metas socioeconômicas ambiciosas, países em desenvolvimento precisam desenvolver capacidade institucional no setor público para estabelecer e implementar políticas públicas, as quais, por sua vez, prescindem de uma reforma na sua contabilidade governamental. O valor social da reforma na contabilidade governamental repousa, portanto, na sua contribuição para as metas de desenvolvimento, inclusive de redução da pobreza. Essa fundamentação tem conduzido os doadores e os financiadores internacionais e multilaterais a endossar as Normas Internacionais de Contabilidade para o Setor Público (NICSPs) e a sua adoção em países em desenvolvimento. A ênfase em assegurar a integridade financeira e a mudança para o regime de competência pode tornar as NICSPs mais úteis na reforma da contabilidade pública em países em desenvolvimento.

Palavras chave: Países em Desenvolvimento; Construção de Capacidade Institucional; Reforma da Contabilidade Governamental; Normas Internacionais de Contabilidade para o Setor Público (NICSPs); Regime de Competência. 


\section{ABSTRACT}

With the purpose of reaching ambitious socioeconomic goals, developing countries need to evolve their institutional capacity in the public sector to establish and implement public policies, which, on their turn, prescind a reform in its government accounting. The social value of reform in government accounting lies, therefore, in its contribution to the development goals, including decrease of poverty. This grounding has lead international and multilateral donors and funders to endorse the International Public Sector Accounting Standards (IPSAS) and its compliance by developing countries. The emphasis on ensuring financial integrity and the change to the accrual accounting can make the IPSAS more useful in reforming the public accounting in developing countries.

Key words: Developing Countries; Institutional Capacity Development; Reform in Government Accounting; International Public Sector Accounting Standards (IPSAS); Accrual aAccounting.

\section{RESUMEN}

Con el objetivo de alcanzar metas socioeconómicas ambiciosas, países en vías de desarrollo precisan desarrollar capacidad institucional en el sector público para establecer e implementar políticas públicas, las cuales, por su vez, prescinden de una reforma en su contabilidad gubernamental. El valor social de la reforma en la contabilidad gubernamental reposa, por tanto, en su contribución para las metas de desarrollo, inclusive de reducción de la pobreza. Esa fundamentación ha conducido a los donadores y a los financiadores internacionales y multilaterales a endosar las Normas Internacionales de Contabilidad para el Sector Público (NICSPs) y su adopción en países en vías de desarrollo. El énfasis en asegurar la integridad financiera y la mudanza para el régimen de competencia puede tornar las NICSPs más útiles en la reforma de la contabilidad pública en países en vías de desarrollo.

Palabras clave: Países en Vías de Desarrollo; Construcción de Capacidad Institucional; Reforma de la Contabilidad Gubernamental; Normas Internacionales de Contabilidad para el Sector Público (NICSPs); Régimen de Competencia.

\section{INTRODUÇÃO}

O tema da $10^{\mathrm{a}}$ Conferência Bienal sobre Pesquisa Internacional Comparativa em Contabilidade Governamental (CIGAR), realizada em Poitiers na França, foi enquadrado em uma pergunta: "A reforma da contabilidade governamental é mimetismo, modismo ou necessidade?" Esta questão é, particularmente, pertinente para países em desenvolvimento, que são convidados a investir substancialmente nesse esforço. Se tal reforma for "mimetismo", pode- 


\section{repc}

ria render não mais que uma imitação cômica das práticas ocidentais. Se for um modismo ela renderia pouca coisa de valor duradouro. Este artigo afirma que a reforma da contabilidade governamental é necessária porque fortaleceria a capacidade institucional necessária para se atingirem as metas de desenvolvimento. Também exorta o Comitê de Normas Internacionais de Contabilidade para o Setor Público (IPSASB) a colocar a integridade financeira como uma das suas principais preocupações e a tornar obrigatória a Contabilidade sob regime de competência para os países em desenvolvimento.

\section{REFORMA DA CONTABILIDADE GOVERNAMENTAL EM PAÍSES EM DESENVOLVIMENTO}

\subsection{Uma breve revisão da literatura}

As relações entre a reforma da contabilidade governamental e o desenvolvimento nacional raramente são abordadas na literatura acadêmica existente e estão implícitas somente na literatura profissional. Quatorze anos atrás, Chan, Jones e Luder (1996) observaram que os países em desenvolvimento tinham sido sub-representadas na pesquisa internacional comparativa em contabilidade governamental (CIGAR). Tal negligência foi corrigida. O grupo de Glasgow (Escócia) documentou as experiências de algumas ex-colônias britânicas e francesas na África Oriental e no Norte da África (GODFREY, DEVLIN, MERROUCHE, 1996, 1999); a Grã-Bretanha também influenciou a Malásia (COOMBS, TAYIB, 1999) e o Egito (OUDA, 2001); o grupo de Bodo (Noruega) tem estudado a contabilidade governamental russa pós-soviética (BOURMISTROV, MELLEMVIK, 2000 e 2001); o grupo de Lodz (Polônia), durante muito tempo, acompanhou os desenvolvimentos de contabilidade governamental na Polônia (JARUGA, 1988; NOWAK, BAKALARSKA, 2001); e a China tem sido o foco do trabalho do autor nos últimos anos (CHAN, $1996 \mathrm{e}$ 2000; CHAN, CONG, ZHAO, 2001; CHAN, LI, 2005). Esta literatura principalmente descritiva, no entanto, não produziu teorias que articulassem o relacionamento entre a contabilidade governamental e o desenvolvimento político, econômico e social de um país.

Uma série de manuais resume as experiências e os conselhos dos consultores enviados por organizações internacionais aos países em desenvolvimento e economias em transição: do Banco Mundial (WORLD BANK, 1998), do Fundo Monetário Internacional (CHU, HEMMING, 1991), do Banco Asiático de Desenvolvimento (SCHIAVO-CAMPO, TOMMASI, 1999) e da Organização para a Cooperação e Desenvolvimento Econômico (ALLEN, TOMMASI, 2001). Seus diagnósticos e recomendações estão baseados em práticas ocidentais, que, muitas vezes, são vistas como boas ou até como as melhores do mundo. A reforma da contabilidade governamental é considerada parte da melhoria da gestão financeira pública e, como tal, presume-se que contribua para o desempenho do governo e que, pelo menos indiretamente, contribua para o desenvolvimento de uma nação.

Ambos os corpos de literatura (acadêmica e profissional) transmitem a impressão de que, tomando-se as democracias ocidentais industrializadas como referência, a contabilidade governamental nos países em desenvolvimento seria menos avançada do que 


\section{repc}

em países desenvolvidos. Esta observação lança, de maneira implícita, a hipótese de que exista uma relação entre o desenvolvimento da contabilidade governamental de um país e o seu desenvolvimento político e econômico.

\subsection{O nexo entre a contabilidade governamental e o desenvolvimento nacional}

A contabilidade governamental refere-se aos sistemas de informações financeiras e às práticas de evidenciação financeira. Seu estágio de desenvolvimento resulta da interação entre a oferta e a procura por accountability e transparência financeira governamental. Dado que seja caro produzir e divulgar informações, os governos em todos os tipos de sistemas políticos carecem de incentivos econômicos para fazê-lo. No entanto, alguns sistemas políticos apresentam uma maior demanda por accountability e transparência governamental do que outros, por exemplo, as democracias representativas são mais exigentes do que sistemas políticos autoritários e totalitários. Em uma democracia, o governo é obrigado a ser mais sensível às demandas de informações que the são dirigidas. Este seria o caso dos países desenvolvidos e dos países em desenvolvimento. No entanto, o custo de oportunidade dos recursos usados na melhoria da informação financeira governamental é maior em países em desenvolvimento do que nos países desenvolvidos. Portanto, mesmo se os governos democráticos em países em desenvolvimento estiverem dispostos a empreender a reforma na contabilidade governamental, eles podem ser incapazes financiá-la; já os governos não democráticos de países em desenvolvimento podem ser tanto relutantes em realizá-la, quanto incapazes de financiá-la.

A análise acima sugere duas diferentes estratégias de promoção da reforma na contabilidade governamental em países em desenvolvimento. Nos países onde exista vontade política, apenas o financiamento e o apoio técnico seriam necessários. Em países onde o governo não apresente vontade política e capacidade financeira, as assistências técnica e financeira externa seriam necessárias, mas insuficientes; a reforma política interna poderia ser a chave para a melhoria da sua contabilidade governamental, embora as condições associadas à assistência financeira externa pudessem lhe fornecer incentivos adicionais.

\subsection{As metas de desenvolvimento do milênio e estratégia de redução da pobreza}

Atualmente, há uma oportunidade para se promover a reforma da contabilidade governamental em países em desenvolvimento, ligando-a às metas de desenvolvimento do milênio da Organização das Nações Unidas. Esses objetivos buscam: erradicar a pobreza e a fome extremas; alcançar a educação primária universal; promover a igualdade entre os sexos e a autonomia feminina; reduzir a mortalidade infantil; melhorar a saúde materna; combater o HIV / AIDS, a malária e outras doenças; garantir a sustentabilidade ambiental; e desenvolver uma parceria global para o desenvolvimento (SACHS, 2005, p. 211-213). Muitas dessas metas apresentam objetivos quantificáveis. Por exemplo, a meta de redução da pobreza exige a redução pela metade, entre 1990 e 2015, na proporção de pessoas que 


\section{repec}

sofrem de fome e cuja renda é inferior a um dólar norte-americano por dia. Com o apoio do programa de desenvolvimento das Nações Unidas e outros, cada país de baixa renda elaboraria estratégias de redução da pobreza para atingir os objetivos acima.

De acordo com Jeffrey Sachs (consultor das Nações Unidas contra a pobreza), uma estratégia de redução completa da pobreza, com base nas metas de desenvolvimento do milênio teria cinco partes: (1) um diagnóstico diferencial que identificasse as políticas e os investimentos necessários; (2) um plano de investimento que indicasse o montante e tempo necessário; (3) um plano financeiro que estimasse o tamanho do déficit a ser financiado em parte por doadores; (4) um plano de doadores que detalhasse os compromissos dos doadores ao longo dos anos; e (5) um plano de gestão pública que especificasse os mecanismos de governança e administração para implementar a estratégia (2005, p. 273-274). A reforma da contabilidade governamental pertenceria a esse último componente.

A contabilidade governamental subdesenvolvida, provavelmente, contribui e resulta no que Sachs chamou de armadilhas fiscais e falhas de governança, ao que ele responsabiliza pelo subdesenvolvimento de alguns países. Um governo fiscalmente encurralado não disporia de recursos para pagar pela infraestrutura e outros bens e serviços públicos essenciais ao seu desenvolvimento econômico. As falhas de governança se manifestam na corrupção, na debilidade dos sistemas judiciais que definem os direitos de propriedade e execução dos contratos, bem como na incapacidade para exercer as funções básicas do governo (GRINDLE, 2000). Em casos extremos, o Estado falharia também, causando um fracasso econômico ainda mais expressivo.

\subsection{Os custos e benefícios sociais da reforma da contabilidade governamental}

Um bom sistema de contabilidade governamental não é reconhecido, de modo amplo, como parte importante da infraestrutura institucional de um país. Em vez disso, a contabilidade governamental é geralmente compreendida como uma função burocrática. Para piorar a situação, tal como a fundação de uma casa ou de rede de esgoto subterrâneo, o sistema de contabilidade como uma infraestrutura institucional crítica é muitas vezes invisível até que ela falhe, por exemplo, quando o dinheiro público é desperdiçado e perdido, quando os impostos não são arrecadados, ou quando os seus funcionários não são pagos tempestivamente. Sistemas contábeis melhorados podem facilmente conduzir às melhorias na gestão financeira governamental. No entanto, a contribuição do sistema contábil para a realização de objetivos maiores, tal como a redução da pobreza, é necessariamente indireta e de longo prazo. Por isso, é difícil aferir os seus benefícios sociais.

Além disso, nos países pobres, a reforma da contabilidade governamental enfrenta um dilema moral. Por causa de seus custos, tais reformas competiriam com alimentos, remédios e disponibilização de água potável para os moradores de favelas urbanas. Sob tais circunstâncias, como se poderia justificar o gasto para melhorar a forma como o governo mantém suas contas e produz seus relatórios financeiros? 


\section{repec}

Esse dilema moral é resolvido por meio dos benefícios sociais da contabilidade governamental. A contabilidade governamental em si não reduz a pobreza, mas contribui para o desenvolvimento socioeconômico de um país, por meio do seu efeito sobre a gestão e accountability financeira pública. A contabilidade governamental eficaz permite gerir as finanças do governo de forma harmoniosa e fornece pistas para que a auditoria previna e detecte má conduta financeira. À luz da difusão e da gravidade da corrupção governamental em muitos países em desenvolvimento (ROSE-ACKERMAN, 1999), a garantia de integridade financeira seria uma função extremamente importante para os seus sistemas de contabilidade governamental. Apenas uma gestão pública ética e competente poderia implementar programas de redução da pobreza de modo eficiente e eficaz e alcançar outras metas socioeconômicas. Sachs declarou que "[...] nenhum país deveria receber um financiamento mais expressivo a menos que o recurso (para a redução da pobreza) pudesse ser auditado."

É importante que os contabilistas eduquem os funcionários públicos e o público sobre o valor social da contabilidade governamental. O sistema de contabilidade são os "nervos do governo", para usar a expressão de Karl Deutsch (DEUTSCH, 1966), porque ela é o centro de comando e de controle financeiro governamental. Um sistema de contabilidade governamental pode ser rudimentar ou sofisticado. Tal como em uma empresa (SIMON, 1954), um sistema de contabilidade governamental, no mínimo, mantém registros financeiros precisos. Um meIhor sistema de contabilidade governamental direciona a atenção dos tomadores de decisões políticas e dos gestores para áreas problemáticas e, na melhor das hipóteses, um sistema de contabilidade governamental fornece informações úteis para a tomada de decisão.

Assim, é preciso certa dose de clarividência e discernimento para se fazerem investimentos na reforma da contabilidade governamental, ou seja, a previsibilidade para antecipar as consequências da má contabilidade ou da sua ausência, e a reflexão para ligar a contabilidade ao desempenho do governo e, eventualmente, à consecução dos objetivos sociais. A contabilidade governamental pode contribuir para o desenvolvimento socioeconômico de um país, fornecendo informações aos gestores públicos e àqueles que os mantêm responsáveis no desempenho das funções fundamentais do Estado. Como uma função de apoio, a contabilidade não apresenta valores próprios e não decide sobre a alocação de recursos. No entanto, uma vez que essas decisões são tomadas, o sistema de contabilidade executa a função crítica de seguir o fluxo monetário. Desse modo, a contabilidade e suas funções aliadas, incluindo a concepção de sistema de informação, o controle interno, a pré e a pós-auditoria, a administração da receita e da despesa pública, assegurariam que os recursos fossem utilizados para os fins pretendidos. Se o objetivo é o desenvolvimento socioeconômico, a contabilidade pode ajudar a atingir esse objetivo, assegurando a aderência legal e contratual e facilitando a gestão financeira e a promoção da transparência e da accountability. 


\section{repc}

\section{AADOÇÃO DAS NICSPS COMO REFORMA DA CONTABILIDADE GOVERNAMENTAL}

\subsection{Elementos da reforma da contabilidade governamental}

A reforma da contabilidade governamental em países em desenvolvimento requer apoio político e de gestão. O sucesso depende da capacidade de mobilizar o apoio dos líderes políticos, que ajustam o tom pela exigência de uma maior accountability e transparência. Sua determinação política encontrará uma melhor possibilidade de realização se for reforçada pelo apoio de ministros e altos funcionários, a fim de alterar a forma pela qual o governo opera. Devido à sua natureza técnica, o marketing das propostas de reforma para os políticos e para os gestores do topo da hierarquia torna-se uma tarefa desafiadora.

O apoio material também é essencial para o sucesso da reforma da contabilidade governamental. $\mathrm{O}$ apoio orçamentário suficiente é necessário para a aquisição de software e hardware, e para se contratar uma equipe qualificada. Em muitos países em desenvolvimento, a escassez de pessoal técnico impõe uma restrição grave, portanto, os recursos humanos são outro obstáculo a se superar.

A reforma implica mudanças políticas e procedimentos da contabilidade governamental. A maioria dos países apresenta algum tipo de regra e de regulamento para os seus sistemas de contabilidade governamental, apesar de seus arranjos institucionais, para o estabelecimento de regras e regulamentos, poderem ser diferentes. O Comitê de Normas Internacionais de Contabilidade para o Setor Público (IPSASB) exorta todas as nações a adotar as NICSPs. Uma vez que as NICSPs são o centro dos esforços da profissão contábil em todo o mundo para influenciar as reformas de contabilidade governamental em países em desenvolvimento (IPSASB, 2005; SUTCLIFFE, 2003), a próxima seção examina a relevância das NICSPs nos países em desenvolvimento.

\subsection{As NICSPs e os países em desenvolvimento}

As NICSPs destinam-se aos países em desenvolvimento. A maioria dos países desenvolvidos de língua inglesa já apresenta normas de contabilidade governamentais que são similares ou mais rigorosas do que as NICSPs. Mesmo que as normas nacionais sejam bastante diferentes das NICSPs, as outras nações desenvolvidas estão sob pouca pressão interna ou externa pela adoção das NICSPs. Os países em desenvolvimento, por outro lado, enfrentam uma situação diferente. O Banco Mundial aprova o uso das NICSPs na contabilização de sua ajuda financeira aos países em desenvolvimento. Além disso, as NICSPs são apresentadas como as melhores ideias de contabilidade governamental que a profissão contábil global teria para oferecer. As NICSPs, portanto, tornaram-se reconhecidas como referência para se avaliar e melhorar a contabilidade governamental nos países em desenvolvimento.

Os objetivos iniciais das NICSPs eram promover uma maior accountability governamental em todos os países; melhorar a qualidade e a confiabilidade na contabilidade e nos 


\section{repc}

relatórios financeiros; melhorar o desempenho econômico e financeiro; e melhorar a gestão e a disciplina financeira e a harmonização internacional das exigências de informação (IFAC, 1996, p. 2). A declaração desses louváveis objetivos teria conduzido ao desenvolvimento de NICSPs que fossem relevantes para os países em desenvolvimento? A avaliação preliminar do autor é extremamente negativa.

Mesmo as NICSPs não sendo concebidas apenas para os países em desenvolvimento, seria razoável inferir, a partir dos seus patrocinadores financeiros, que os países em desenvolvimento se destinavam como seus principais beneficiários. Assim, é intrigante o fato de os países em desenvolvimento não receberem atenção precoce, apesar das responsabilidades institucionais dos patrocinadores e de seus interesses aparentes. Nos últimos anos, o comitê das NICSPs abordou os países em desenvolvimento de duas maneiras. Primeiro, ele publicou um conjunto abrangente de "NICSP em regime de caixa" em 2003. Dado que as exigências dessa norma estariam mais próximas das práticas atuais e que seriam menos onerosas para a implementação, corria-se o risco de que elas se tornassem, de fato, as NICSPs para os países em desenvolvimento. Se fosse esse o caso, seria uma situação infeliz, como se irá discutir na próxima seção. Em segundo lugar, o comitê das NICSPs está em processo de elaboração de uma norma sobre a evidenciação para a ajuda externa sob regime contábil de caixa (IFAC, Exposure Draft 24, emitida em fevereiro de 2005). O regime de caixa, por definição, exclui o reconhecimento subsídios a receber e de empréstimos a pagar e outros ativos e passivos não monetários. Essas duas normas, dificilmente, poderiam ser consideradas como uma resposta adequada às necessidades da reforma da contabilidade governamental em países em desenvolvimento.

\section{3 . Regime de competência para países em desenvolvimento}

O comitê das NICSPs e seu antecessor não ofereceram justificativas teóricas para isentar os governos de países em desenvolvimento do regime contábil de competência, a não ser pelas alegações de inviabilidade devido ao custo e a outras poucas restrições. $\mathrm{Na}$ opinião do autor, esta não é uma posição defensável, por permitir que o regime de caixa comprometa os objetivos de promoção da accountability financeira governamental. Independentemente do regime contábil utilizado, um governo é responsável pelos passivos referentes às suas dívidas, aos credores, aos fornecedores, aos funcionários, aos doadores e a outros tipos credores. A falta de informação completa, confiável e oportuna sobre essas obrigações financeiras enfraquece a capacidade e o incentivo desse governo devedor de cumprir com as suas responsabilidades. Inversamente, a falta de informações completas, confiáveis e oportunas sobre os recursos financeiros não monetários, tais como investimentos, tributos a receber, contas a receber e créditos a receber, dificultaria o esforço de arrecadação governamental e reduziria a sua capacidade de transformar esses recursos em caixa para pagar as suas obrigações. A incapacidade de confrontação de ativos e passivos financeiros, em termos de quantidade e tempo, é uma das causas fundamentais 


\section{repc}

dos problemas de liquidez e solvência, o que poderia se converter em uma crise fiscal de grandes proporções. Os governos de nações pobres em desenvolvimento apresentariam uma demanda, talvez mesmo uma grande necessidade de obter informações contábeis em regime de competência.

A atual co-existência de NICSPs em regime de caixa e em regime de competência resulta da recusa do Comitê para Setor Público em reconhecer a legitimidade de "vários pontos ao longo do espectro entre o regime de caixa e o regime de competência" (IFAC PUBLIC SECTOR COMMITTEE, 2000). É inadequada, na opinião do autor, a apresentação de critérios contábeis alternativos, como se só existissem, por exemplo, as cores preta e branca. Há razões válidas ao fato de existirem, e deveriam existir, vários graus intermediários de competência. Os governos mantêm diferentes tipos de recursos financeiros de vários graus de liquidez e possui diferentes tipos de recursos econômicos. Da mesma forma, os governos têm obrigações financeiras de diferentes graus de exigibilidade. É equivocada a insistência na dicotomia entre "caixa versus competência".

Não é aconselhável para países em desenvolvimento a adoção do regime de competência, a ponto de reconhecer e evidenciar a infraestrutura e os bens culturais. Seria apropriado o registro dos ativos e passivos na medida em que os seus benefícios excedessem os seus custos. Como indicado na Tabela 1, existem graus de competência, variando da leve, passando pela moderada até a forte. O reconhecimento e a mensuração correta dos recursos financeiros circulantes e dos passivos circulantes seriam o ponto de partida de qualquer projeto de contabilidade sob o regime de competência. Posteriormente, os recursos financeiros realizáveis e os passivos exigíveis a longo prazo poderiam ser adicionados. Depois, os ativos fixos operacionais (por exemplo, edifícios públicos e equipamentos) e os passivos contingentes poderiam ser reconhecidos e evidenciados. Esta abordagem progressiva simétrica é preferível para os países em desenvolvimento. O gradualismo leva em consideração o custo, a necessidade de se acumular experiência, o apoio político seguro e a capacidade de se construírem sistemas e se desenvolverem recursos humanos. $O$ reconhecimento simétrico de ativos e passivos de mesma natureza (por exemplo, contas a receber e contas a pagar) e o prazo semelhante (por exemplo, ativos e passivos circulantes) impediria a evidenciação incompleta e distorcida da posição financeira.

Tabela 1 - Graus de competência

\begin{tabular}{lll}
\hline Grau & Ativos reconhecidos & Passivos reconhecidos \\
\hline Competência fraca & Recursos financeiros circulantes & Passivos circulantes \\
Competência moderada & Recursos financeiros realizáveis a longo & $\begin{array}{l}\text { Passivos de longo prazo, além dos } \\
\text { prazo, além dos circulantes }\end{array}$ \\
circulantes \\
Competência forte & $\begin{array}{l}\text { Recursos de capital, além dos circulantes } \\
\text { e realizáveis a longo prazo }\end{array}$ & $\begin{array}{l}\text { Passivos contingentes, além dos } \\
\text { circulantes e de longo prazo }\end{array}$ \\
\hline
\end{tabular}


Pelas razões enumeradas anteriormente, todos os governos deveriam adotar imediatamente a "competência fraca" para a contabilidade e a evidenciação de ativos e passivos circulantes. Os governos deveriam, em seguida, mover-se com toda a velocidade deliberada para a "competência moderada", a fim de trazer os ativos financeiros realizáveis e passivos exigíveis a longo prazo para as suas contas e demonstrações financeiras. No entanto, a "competência forte" deveria ser implementada com cautela, levando-se em conta os seus muitos problemas conceituais e de mensuração.

A classificação sistemática dos ativos e passivos não só esclarece os diferentes graus de competência para fins de contabilidade e relatórios. Esse exercício apresenta um importante benefício, ou seja, o governo terá bases de dados de seus recursos e obrigações e estará em melhor posição para alcançar níveis adequados de liquidez e solvência.

Concluindo, competência leve e moderada é uma necessidade e, não, um luxo, mesmo nos países em desenvolvimento. Um sistema de contabilidade pode acomodar a contabilização em regime de caixa, no entanto, um sistema de contabilidade sob o regime de caixa não pode incluir o regime de competência. Portanto, o autor convida o comitê das NICSPs a revogar a NICSP sob regime de caixa e a emitir suas disposições sob o regime de competência.

\section{RUMO A UMA CONTABILIDADE GOVERNAMENTAL EFICAZ}

\subsection{A natureza geral das NICSPs}

O programa NICSP evoluiu em duas fases. De 1996 a 2002, o comitê da IFAC para o setor público, essencialmente, importou normas contábeis e de relatório financeiro do setor privado para o setor público, fazendo alterações relativamente pequenas. Desde 2003, o Comitê das NICSPs tem conscientemente enfocado questões que são próprias do setor público. Essas questões incluem os tributos e outras transações sem contraprestação; as implicações do orçamento para os relatórios financeiros; e os compromissos com a política social. Ambas as fases estão no domínio da contabilidade financeira, que tem sido chamada de "a linguagem dos negócios".

Para o público em geral e para a maioria dos funcionários do governo, o orçamento ainda é o principal documento financeiro governamental. A crescente importância da contabilidade financeira no setor público, como tipificado pela emergência das NICSPs na cena mundial, reflete a crença no poder do registro financeiro, objetivo que foi creditado pela indução do comportamento business-like (CROSBY, 1997, p. 200). As NICSPs estão fundamentadas na partida dobrada, que é considerada uma das "medidas de realidade" que tornou possível as práticas comerciais modernas (CROSBY, 1997). Por fundamentar os dados financeiros em operações e acontecimentos passados, a contabilidade financeira governamental fornece uma verificação da realidade contra as previsões e os planos especulativos futuros no orçamento. Esta parece ser a justificativa não declarada de as NICSPs seguirem 


\section{repec}

a padronização das International Financial Reporting Standards (IRFS) (para empresas).

A contabilidade financeira governamental também se diferencia dos sistemas estatísticos governamentais. Tais sistemas incluem o Government Finance Statistics do FMI e os sistemas de contas nacionais. O que faz com que a contabilidade financeira se diferencie deles é que, como uma "prática social e institucional" (HOPWOOD, MILLER, 1994), a contabilidade é um instrumento de accountability. A promoção da prestação de contas por meio de uma maior transparência, que os contabilistas tradicionalmente chamam de full disclosure, é um objetivo explícito das NICSPs. Em particular, as NICSPs enfatizam a accountability do governo perante os seus cidadãos, eleitores, representantes e o público em geral (IFAC, 2003, p. 19 e 35).

Na segmentação desses usuários potencialmente carentes, o comitê das NICSPs assumiu um grande desafio. Esses usuários seriam carentes porque alguns governos aparentemente decidiram que os custos de informá-los superariam os respectivos benefícios. O comitê das NICSPs está procurando equilibrar a balança de poder entre governo e certas partes, salientando o direito à informação. O dilema é que os governos que têm uma maior necessidade de melhorar sua accountability e transparência financeira são os mais prováveis a ser reticentes e menos capazes de adotar as NICSPs. Dada a sua falta de poder de execução, o comitê tem sabiamente se aliado aos fornecedores de auxílio ao desenvolvimento. Essas organizações têm o incentivo e a capacidade de demandarem boa contabilidade e relatórios financeiros informativos de seus beneficiários. Ao mesmo tempo, eles também reconheceram que exigências múltiplas e sobrepostas são onerosas para os países em desenvolvimento. O processo das NICSPs forneceu um mecanismo de coordenação para reduzir os custos de accountability. Esta é aparentemente a razão pela qual o Banco Mundial, o Fundo Monetário Internacional, as Nações Unidas para o Desenvolvimento e o Banco Asiático de Desenvolvimento têm apoiado o processo das NICSPs. Para eles, as NICSPs servem como um instrumento comum para promover a transparência e a accountability dos programas e das atividades que eles financiam e do governo em geral. Para seu crédito, essas organizações internacionais têm resolvido o problema do "efeito carona", que, de outra forma, perturbaria a produção das NICSPs como um bem público global.

Entre as duas dezenas de NICSPs, as normas mais importantes são a primeira e a segunda, as quais exigem que os governos emitam demonstrações financeiras governamentais com escopo amplo sob o regime de competência ao final de cada ano fiscal. A aplicação dessas normas, com efeito, obriga um governo a abrir os seus livros para usuários externos. Como mencionado anteriormente, as NICSPs procuram equilibrar a relutância de alguns governos em evidenciar e o direito do público de saber. No entanto, as NICSPs tratam de transparência como uma virtude autoevidente do governo. Infelizmente, essa opinião não é compartilhada em todo o mundo. A maioria dos governos usa a contabilidade para controlar suas próprias atividades, mas alguns países têm a cultura política e as leis de incentivo que exigem relatórios financeiros externos. O comitê das NICSPs, bem como 
seus patrocinadores e apoiadores, está fazendo uma afirmação audaciosa de que a accoutability e a transparência fiscal seriam uma norma universal. O que se faz necessário agora é a realização de ações para tornar mais úteis as NICSPs nas quais essas normas não sejam observadas de modo satisfatório.

\subsection{Tornando as NICSPs (mais) úteis aos países em desenvolvimento}

Os países em desenvolvimento enfrentam o desafio de elevar o padrão de vida de seus povos. As metas de desenvolvimento do milênio das Nações Unidas e as estratégias de redução da pobreza só podem ser percebidas se os governos e as autoridades governamentais tiverem a capacidade necessária para gerir os recursos escassos, principalmente os financeiros. Nisso reside a contribuição dos contabilistas e dos auditores para os programas de construção de capacidade institucional. O sucesso na reforma da contabilidade governamental depende de apoio político e de gestão, além da disponibilidade de recursos orçamentários, humanos e de tecnologia de informação. O hardware para sistemas de contabilidade governamental é inútil sem softwares aplicativos e torna-se negligente sem as respectivas normas de contabilidade.

As NICSPs são um parente recém-chegado ao clube de normas e normatizadores contábeis nacionais e internacionais. Sob a liderança inicial e a influência, principalmente, de países de língua inglesa, o comitê para o setor público da IFAC decidiu enfatizar as demonstrações financeiras consolidadas do final de cada exercício. Este tipo de informação refere-se, na melhor das hipóteses, apenas à accountability financeira externa. A orientação histórica de informações de contabilidade financeira limita ainda mais a sua utilidade para o controle e o planejamento, que exige informação em tempo real e é voltada para o futuro. As demonstrações financeiras resumidas, muitas vezes, não são suficientemente detalhadas de modo coincidente com o grau de responsabilidade dos gestores. As NICSPs, baseadas em demonstrações financeiras, não são realmente concebidas para evidenciar a responsabilidade dos subordinados aos seus superiores, e do Executivo para com o Legislativo. Como tal, as NICSPs podem fazer apenas uma contribuição limitada à construção de capacidade institucional em países em desenvolvimento.

As NICSPs pressupõem a existência de um sólido sistema de controle interno da gestão financeira e de um sistema contábil governamental. Os recentes escândalos financeiros ocorridos nos Estados Unidos, como os da Enron e da WorldCom, têm demonstrado que a confiabilidade das demonstrações financeiras baseadas na contabilidade pode ser prejudicada pela manipulação das operações subjacentes. Essa situação também pode acontecer nos relatórios financeiros do setor público. A confiabilidade dos números em suas demonstrações financeiras não pode ser tida como certa, considerando-se a vulnerabilidade do governo em países em desenvolvimento à má conduta financeira, mesmo que as NICSPs sejam utilizadas. Por esta razão, os profissionais de contabilidade têm uma participação na luta global contra a corrupção governamental. 
Segundo a Reuters (2003), o Banco Mundial estimou que "[...] cerca de cinco por cento do produto interno bruto mundial é perdido para a corrupção como desvio de verbas e peculato." Como resultado de tais estatísticas, o combate à corrupção se tornou uma prioridade das organizações internacionais e de muitos países em desenvolvimento. No final do ano 2003, 114 países assinaram a Convenção das Nações Unidas contra a corrupção. 0 Banco Mundial estabeleceu um escritório de integridade financeira para investigar denúncias de corrupção. Um estudo recente de Keefer e Khemani (2004), do grupo de desenvolvimento do Banco Mundial, constatou que "[...] mesmo em países em desenvolvimento que são democráticos, os políticos têm frequentemente incentivos para desviar recursos para receitas políticas e transferências privadas que beneficiam alguns poucos cidadãos em detrimento de muitos."

A corrupção oficial ameaça a legitimidade de um governo e a sua autoridade, e reduz a quantidade de dinheiro público disponível para financiar os serviços públicos. A gestão financeira incompetente é dispendiosa em termos de ineficiência e de ruptura a que induz o próprio governo e o sistema econômico. A má gestão do dinheiro resulta em perdas financeiras. Investimentos financeiros imprudentes podem levar a maior exposição ao risco e a menores retornos. A arrecadação atrasada ou a subarrecadação de tributos reduz a quantidade de recursos financeiros disponíveis e aumenta os riscos de liquidez e de solvência. A falta de pagamento de contas, quando são devidas potencialmente, pode criar problemas de liquidez ou solvência para funcionários, fornecedores e outros credores. A falta de pagamentos de juros e reembolsos de capital aos detentores de títulos prejudica a posição creditícia e pode elevar o custo de captação de novos empréstimos. Por todas essas razões, os contabilistas do governo, os auditores e os gestores financeiros estão na linha de frente na luta contra a corrupção.

Atualmente, as NICSPs parecem ter por certo que as transações são devidamente autorizadas e apropriadamente executadas. O papel das normas contábeis é o de decidir se reconhece as consequências dessas operações e, em caso afirmativo, a forma de mensurar e evidenciar esses efeitos. Os organismos de normatização contábil estão certamente cientes da possibilidade de que as operações possam ser "estruturadas" para se tirar proveito do que as normas contábeis permitem. Mas é principalmente do auditor o papel de lidar com esse fenômeno. Da mesma forma, as transações não autorizadas e as transações inadequadamente executadas são questões de preocupação para os auditores e para a administração. Essa atitude negligencia a confiança do auditor sobre a capacidade do sistema contábil em gerar pistas para a auditoria.

Além das considerações econômicas e sociais mais amplas, os efeitos negativos da má conduta financeira sobre os relatórios financeiros do governo deveriam motivar o comitê das NICSPs a prestar uma atenção explícita à integridade financeira. Especificamente, o comitê poderia realizar ou promover uma investigação sobre as implicações da integridade financeira, ou da falta dela, para as NICSPs. Em princípio, controles internos 
fracos poderiam levar a números não confiáveis nas demonstrações financeiras. Menos é empiricamente conhecido sobre como e em que medida os números contábeis do governo são distorcidos pelo comportamento antiético.

Geralmente, as normas de contabilidade assumem um papel mais importante como requisitos de responsabilidade social em países que exigem elevados padrões de comportamento ético. As normas de contabilidade governamental em vigor tornam-se normas de accountability do governo (recentemente o General Accounting Office dos Estados Unidos foi rebatizado para Government Accountability Office). O governo deve responder pelos recursos ou pela autoridade que recebe de outras pessoas na sociedade e na economia. O governo fornece tanto bens públicos quanto bens privados em troca da autoridade para governar, assim como os recursos econômicos e financeiros e os requisitos de accountability do governo estão expressos em termos contratuais de política, contratos sociais, econômicos e dos contratos que o governo celebra com seus stakeholders (vide Tabela 2). A perspectiva "ativo-passivo" e a contabilidade sob o regime de competência descritos na Tabela 1 são compatíveis com essa teoria contratual do governo: os ativos do governo provêm das contribuições voluntárias e involuntárias dos stakeholders, e as suas dívidas são provenientes de incentivos para com os stakeholders.

Tabela 2 - Stakeholders do governo

\begin{tabular}{lll}
\hline Stakeholderes & Contribuição para o governo & Indução governamental \\
\hline Eleitores & Legitimidade política & \\
Contribuintes & Recursos financeiros & Bens e serviços públicos \\
Receptores dos serviços & Apoio político & \\
Doadores & Recursos financeiros & Cooperação no uso dos recursos \\
Credores & Recursos financeiros & Amortização e juros \\
Empregados & Serviços & Compensação \\
Contratados & Bens e serviços & Pagamentos \\
\hline
\end{tabular}

Concluindo, o fundamental para o desenvolvimento da contabilidade sob o regime de competência em países em desenvolvimento é a capacidade de se identificar e de se mensurar os ativos e passivos do governo. A corrupção tende a resultar na subavaliação dos ativos ou no exagero dos passivos governamentais. A menos que seja assegurada a integridade financeira, a credibilidade das informações financeiras do governo é ameaçada. Assim, tanto a garantia da integridade financeira quanto a contabilidade correta sob o regime de competência são as contribuições dos profissionais para os países em desenvolvimento. 


\section{repec}

\section{REFERÊNCIAS BIBLIOGRÁFICAS}

ALLEN, R.; TOMMASI, D. Managing Public Expenditure: A Reference Book for Transition Countries, Paris: OECD, 2001.

BOURMISTROV, A.; MELLEMVIK, F. Russian Local Government Accounting: New Norms and New Problems, In: CAPERCHIONE, E.; MUSSARI, R. (eds). Comparative Issues in Local Government Accounting. Boston: Kluwer Academic Publishers, p. 159-174, 2000.

BOURMISTROV, A.; MELLEMVIK, F.. Accounting and Democratic Governance: A Comparative Study of One Norwegian and One Russian County.,In: BAC, A.(ed). International Comparative Issues in Government Accounting. Dordrecht, The Netherlands: Kluwer Academic Publishers, p. 91-122, 2001.

CHAN, J. L., JONES, R. H. ;LUDER, K. G. Modeling Government Innovations: An Assessment and Future Research Directions. In: CHAN, J. L., JONES, R. H. ;LUDER, K. G. Research in Governmental and Nonprofit Accounting. Greenwich, Connecticut: JAI Press Inc, vol. 9, p. 1-19, 1996.

CHAN, J. L . A Sino-American Comparison of Budget and Accounting Coverage. In: Caperchione, E. and Mussari, R., eds., Comparative Issues in Local Government Accounting, Kluwer Academic Publishers, Boston, p. 11-34.

CHAN, J. L., CONG, S. H.;ZHAO, J. Y. The Effects of Reform on China's Public budgeting and Accounting System. In BAC, A., (ed). International Comparative Issues in Government Accounting. Dordrecht, The Netherlands: Kluwer Academic Publishers, p. 297-314, 2001.

CHU, K-Y.; HEMMING, R. Public Expenditure Handbook: A Guide to Public Policy Issues in Developing Countries. Washington, D.C: International Monetary Fund, 1991.

COOMBS, Hugh M.; Mohamad Tayib, (2000), «Financial Reporting Practice: A Comparative Study of Local Authority Financial Reports Between the UK and Malaysia», CAPERCHIONE, E.; MUSSARI, R. (eds). Comparative Issues in Local Government Accounting. Boston: Kluwer Academic Publishers, p. 53-68, 2001.

DEUTSCH, K. W. The Nerves of Government: Models of Political Communication and Control, New York: The Free Press, 1966. 
GODFREY, A. D., DEVLIN, P.J. and MERROUCHE, C. Governmental Accounting in Kenya, Tanzania and Uganda. In: Chan, J.L. (ed). Research in Governmental and Nonprofit Accounting, Vol. 9, Greenwich, Connecticut : JAI Press, p. 193-208, 1996.

GODFREY, A. D., MERROUCHE, C.; DEVLIN, P.J. A Comparative Analysis of the Evolution of Local Governmental Accounting in Algeria and Morocco. In: COPLEY, P.A.; SANDERS, G. D. (eds). Research in Governmental and Nonprofit Accounting, Vol. 10, Greenwich, Connecticut : JAI Press, p. 201-234, 1999.

GRINDLE, Merilee S. Ready or Not: The Developing World and Globalization. In: NYE, J.S.; DONAHUE, J.D., (eds). Governance in a Globalizing World. Washington, D.C.: Brookings Institution Press, p. 178-207, 2000.

HOPWOOD, A.; MILLER, P. (eds). Accounting as a Social and Organizational Practice, Cambridge: Cambridge University Press, 1994.

IFAC. International Federation of Accountants. Responding to an Increasing Demand for Accountability in the Public Sector. IFAC Quarterly, October, 1996.

. Handbook on International Public Sector Accounting Standards. New York: IFAC.

, International Public Sector Accounting Standards Board, Exposure Draft 24, Financial Reporting Under the Cash Basis of Accounting - Disclosure Requirements for Recipients of External Assistance, New York: IF AC, 2005.

, International Public Sector Accounting Standards Board. Background and Update, unpublished paper, March, 2005.

Public Sector Committee. Study 11, Government Financial Reporting: Accounting Issues and Practices. New York: IFAC, May, 2001.

JARUGA, A. Governmental Accounting, Auditing and Financial Reporting in East European Countries. In CHAN, J.L.; JONES, R. H. (eds). Governmental Accounting and Auditing: International Comparisons. London: Routledge, p. 105-121, 1998.

KEEFER, P.; KHEMANI, S. Democracy, Public Expenditure and the Poor,» World Bank Research Observer. Washington D.C.: World Bank, 2004. 
NOWAK, W.A.; BAKALARSKA, B. Polish Public Sector Accounting in Transition: The Landscape after 1999 Step in the State Redefining. In BAC, A. ed., International Comparative Issues in Government Accounting, Kluwer Academic Publishers, Dordrecht, The Netherlands, p. 265-278, 2001.

OUDA, Hassan A.G. Central Governmental Accounting of Egypt and the Netherlands: Similarities and Differences. In: BAC, A. (ed), International Comparative Issues in Government Accounting, Dordrecht, The Netherlands: Kluwer Academic Publishers,p. 71-90, 2001.

ROSE-ACKERMAN, S. Corruption and Government: Causes, Consequences and Reform, Cambridge: Cambridge University Press, 1999.

REUTERS World Bank urges crackdown on government corruption, 10 December, 2003.

SACHS, J. D. The End of Poverty: Economic Possibilities for Our Time. New York: Penguin Books.

SCHIAVO-CAMPO, S.; TOMMASI, D. Managing Government Expenditure, Asian Development Bank, Manila, 1999.

SIMON, H. A. (1954), Centralization vs. Decentralization in Organizing the Controller's Department, New York: Controllership Foundation, 1954.

SUTCLIFFE, P. The Standards Programme of IFAC's Public Sector Committee. Public Money and Management, January, p. 11-12, 2003.

WORLD BANK. Public Expenditure Management Handbook, Washington, D.C.: World Bank, June 1998. 